\title{
MAPEAMENTO DA DINÂMICA DA COBERTURA E USO DA TERRA NA BACIA HIDROGRÁFICA DO RIO SÃO JOÃO, RJ
}

\section{Mapping the Dynamics of Land cover and Land Use in the watershed of São João River, RJ}

Vinicius da Silva Seabra Professor Adjunto, Faculdade de Formação de Professores, UERJ vinigeobr@gmail.com

Carla Madureira Cruz Profa. Adjunta, Depto. de Geografia, UFRJ. Bolsista Produtividade em Pesquisa, CNPq carlamad@gmail.com

Artigo recebido em 13/11/2012 e aceito para publicação em 17/02/2013

Resumo: As paisagens são compreendidas como resultado da interação entre seus elementos naturais formadores e suas permanentes modificações condicionadas, ou não, pelas intervenções do homem. Dentro desta concepção, torna-se relevante compreender o histórico de ações/intervenções humanas sobre a superfície terrestre, já que muitas das mudanças ocorridas no passado condicionam processos que acontecem no presente, tendo com isso um papel fundamental na organização do espaço geográfico. Sendo assim, o objetivo deste artigo foi analisar a dinâmica da paisagem na bacia hidrográfica do rio São João (BHRSJ) ao longo dos últimos 35 anos através do mapeamento da evolução da Cobertura e Uso da Terra. Esta análise foi realizada a partir de mapas temáticos (1:100.000), gerados por classificação baseada em objetos, utilizando uma imagem do satélite Landsat 4 MSS (1975) e 3 imagens do satélite Landsat 5 TM $(1985,1995,2010)$, todas referentes ao período seco. Os mapas temáticos gerados foram inseridos em um ambiente SIG, onde foram processadas análises que forneceram subsídios para a compreensão e localização das mudanças ocorridas na BHRSJ nos últimos 35 anos e, consequentemente, forneceram elementos importantes para análise da evolução da paisagem em toda área. As análises realizadas a partir do mapa de evolução da Cobertura e Uso da Terra, e as quantificações das mudanças ocorridas nos últimos 35 anos, permitiram a identificação de importantes transformações, das quais podemos destacar: a perda de coberturas naturais, a perda de corpos hídricos naturais e o surgimento de novos corpos hídricos (artificiais).

Palavras-chave: Dinâmica da paisagem, uso e cobertura da Terra, classificação de imagens baseada em objetos, análise espacial.

Abstract: $\quad$ The landscapes are understood as result of the interaction between its natural elements and its permanent conditioned modifications, or not, by human intervention. Within this design, it is important to understand the history of human actions/interventions on the surface, since many of the past changes define processes occurring in the present, thus having a fundamental role in the organization of the geographical space. Therefore, the objective of this study was to analyze the landscape dynamics in the watershed of São João River (BHRSJ) over the last 35 years by mapping the evolution of the Landcover and Landuse. This analysis was based from thematic maps (1:100.000), generated by object-based classification, using an image from the Landsat 4 MSS satellite (1975) and 3 images from the Landsat 5 TM satellite $(1985,1995,2010)$, all related to the dry period. The thematic maps generated were inserted into a GIS environment, where were processed analyses that provided information for the understanding and mapping of the changes occurred in BHRSJ in the last 35 years and thus provided important elements for 
analyzing the evolution of the landscape in the whole area. The analyses performed from the evolution map of the Landcover and Landuse, and the quantification of changes in the last 35 years, allowed the identification of important transformations, of which we highlight: the loss of natural hedges, the loss of natural water bodies and the emergence of new water bodies (artificial).

Keywords: Landscape dynamics, land use and cover, object-based image classification, spatial analysis.

\section{INTRODUÇÃO}

Um dos objetivos da Geografia é explicar as razões que condicionam a localização espacial de objetos e eventos na esfera terrestre e desta maneira, assume a responsabilidade de apresentar a razão lógica para a ocorrência dos elementos que compõem a superfície do planeta, suas interrelações e sua organização no espaço.

Neste sentido, podemos afirmar que o termo "paisagem" assume uma considerável importância dentro da análise espacial, constituindo-se como um conceito fundamental da Geografia. Significa afirmar que o estudo da paisagem configura-se, em sua essência, em um estudo genuinamente geográfico, possuindo um papel relevante para a evolução desta ciência.

As paisagens podem ser consideradas como produto da interação entre seus elementos naturais formadores e suas permanentes modificações condicionadas, ou não, pelas intervenções do homem. Dentro desta concepção, torna-se relevante compreender o histórico de ações/intervenções humanas sobre o espaço geográfico, já que muitas das mudanças ocorridas no passado condicionam processos que acontecem no presente, tendo com isso um papel fundamental na organização do espaço geográfico. Tais aspectos garantem aos mapeamentos de cobertura e uso da terra uma significativa importância quando necessitamos realizar estudos voltados para a compreensão da paisagem.

A cobertura da terra é considerada a expressão das atividades humanas na superfície terrestre e está diretamente ligada ao uso da terra e seu manejo. Os estudos que correlacionam a caracterização da cobertura da terra e a análise de seus diferentes usos e manejos são importantes ferramentas para a compreensão da intensidade das mudanças e o tipo das mudanças em determinadas áreas.

Segundo Jansen (2002), as mudanças de Cobertura e Uso da Terra podem ocorrer de duas formas.
A primeira seria a conversão de uma categoria de uso para outra. Como por exemplo, a mudança de cobertura florestal para pastagem. A segunda forma estaria correlacionada ao manejo, e seria a mudança dentro da própria categoria, como uma área que passa de pequenos campos agrícolas para agricultura irrigada.

Além de fornecer as informações necessárias para o reconhecimento da estrutura da paisagem, da organização espacial dos elementos que compõem a paisagem e da análise das pressões socioeconômicas atuais, a evolução da Cobertura e Uso da Terra possibilita a compreensão da intensidade das mudanças e o período em que elas ocorreram; permite a compreensão de suas estruturas no passado; e, além disso, torna viável a determinação dos vetores e tendências das pressões sobre os espaços naturais.

A intensidade com que ocorre determinado uso também é relevante neste tipo de análise. No caso da urbanização, nem sempre o crescimento das áreas ocupadas pode ser considerado mais impactante que o aumento da intensidade das ocupações. O mapeamento de uso e cobertura realizado por Seabra et. al. (2009) no município de Maricá-RJ, apontou que a passagem de uma urbanização rarefeita para um nível mais intenso de ocupação em algumas áreas foi mais impactante que a expansão urbana de outras localidades. A classe "Urbanização Rarefeita" representa as áreas de menor ocupação, com lotes vazios (não construídos) intercalando as casas.

Neste sentido, torna-se importante os estudos e pesquisas que se dediquem em promover avanços metodológicos nos mapeamentos de Cobertura e Uso da Terra, principalmente em recortes espaciais que apresentem grande dinamismo ambiental, tais como as áreas que recebem grandes obras de infraestrutura viária, que sofrem desmatamento para implementação de agricultura ou de atividades pecuárias, ou ainda, as áreas que experimentam um crescimento populacional acelerado. Trabalhos como o de CRK et. al. (2009), Rudel et. al. (2000), Read et. al. (2003), Hecht et. al. 
(2006), por exemplo, destacam a importância do uso de variáveis socioeconômicas (ex: proximidade do sistema viário, pressão populacional e manejo agrícola), percebidas a partir deste tipo de mapeamento, para estudos relacionados à recuperação de áreas degradadas. A Bacia Hidrográfica do Rio São João (BHRSJ) é uma área que passou por grandes mudanças de cobertura e uso da terra, que podem ser observadas principalmente ao longo das últimas quatro décadas.

Este trabalho teve como objetivo analisar a dinâmica da paisagem na BHRSJ ao longo dos últimos 35 anos através do mapeamento da evolução do uso e cobertura da Terra, utilizando classificação baseada em objeto de imagens
Landsat dos anos de 1975, 1985, 1995 e 2010. A escolha da bacia hidrográfica do rio São João (BHRSJ) como área de estudo deve-se a sua grande importância estratégica para o Estado do Rio de Janeiro, sendo uma das principais fontes de abastecimento de água para a região e para as baixadas litorâneas, além de também possuir um alto grau de endemismo de espécies. Localizada na porção leste do Estado do Rio de Janeiro (fig.1), a BHRSJ destaca-se ainda por abrigar grande parte dos últimos remanescentes de Mata Atlântica em áreas de baixada no estado do Rio de Janeiro, com vegetações em diferentes estados de conservação.

Figura 1. Mapa de Localização da BHRSJ

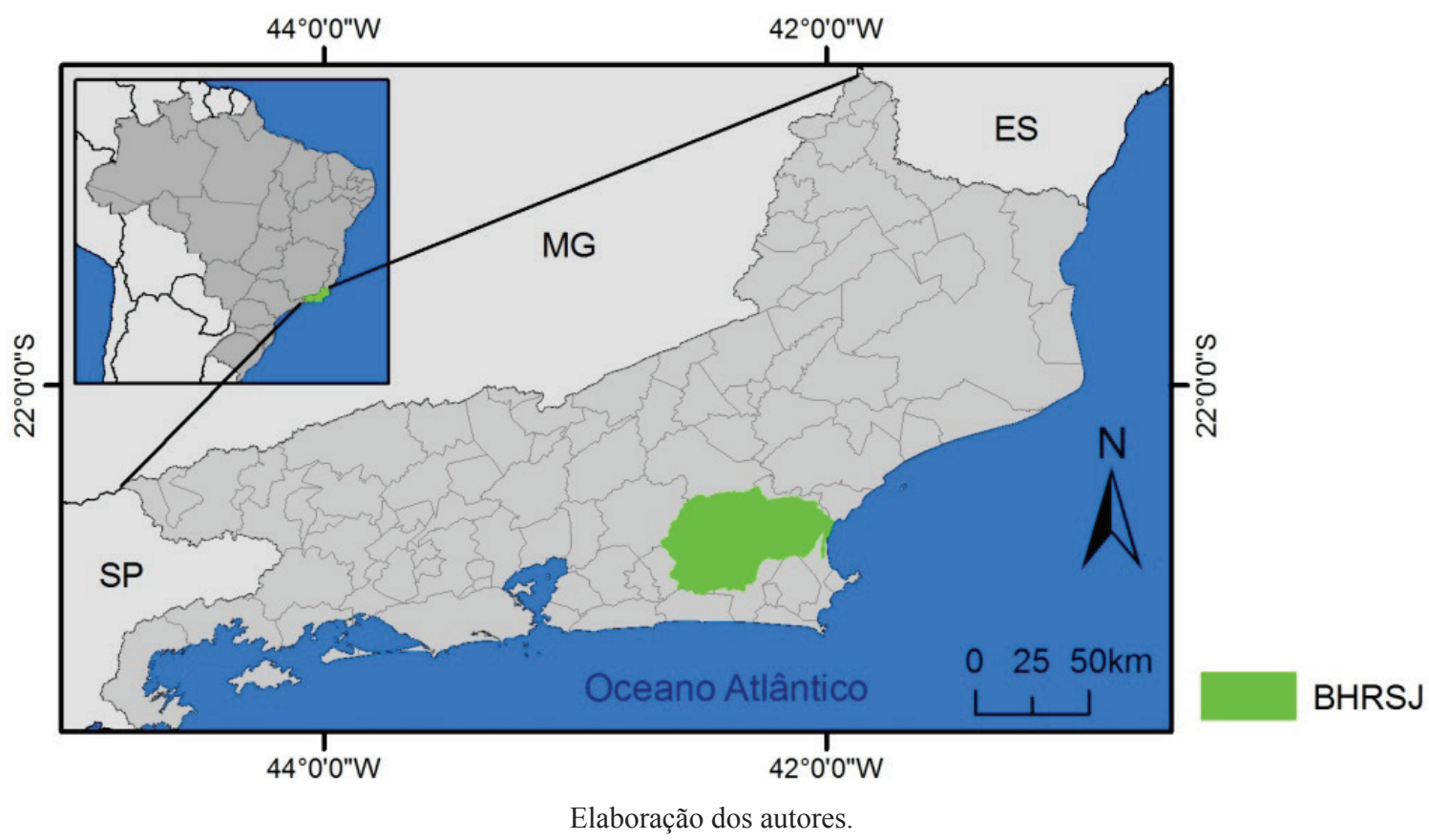

A BHRSJ localiza-se dentro do contexto da Mata Atlântica, situada entre o corredor da Serra do Mar e o litoral atlântico. Esta bacia posiciona-se à oeste da Bacia Hidrográfica da Baía da Guanabara, estando quase que em sua totalidade na Região das Baixadas Litorâneas do Estado do Rio de Janeiro. Segundo o Consórcio Intermunicipal Lagos São João (CILSJ, 2007), a BHRSJ estende-se por $63 \mathrm{~km}$ no sentido leste-oeste e por $43 \mathrm{~km}$ no sentido norte-sul, possuindo uma área total de $2.160 \mathrm{~km}^{2}$.

\section{CLASSIFICAÇÃO DIGITAL BASEADA EM OBJETOS}

A classificação digital é uma das funções prioritárias do processamento digital de imagens de sensoriamento remoto. A maior parte dos mapeamentos temáticos, dentre eles o de Cobertura e Uso da Terra, é embasada em alguma forma de interpretação de fotografias e/ou imagens, sejam provenientes de sensores passivos ou ativos. Esse processo pode ser totalmente visual, o que demanda muito tempo de execução e cuidados com a padronização/uniformização 
de critérios; automático, bastante questionado pela baixa acurácia dos resultados; ou ainda, semiautomático, que busca agregar vantagens dos dois processos anteriores, dando um espaço significativo para a etapa de edição manual (CRUZ et. al., 2009).

Entendemos por classificação digital o processo de extração de informação em imagens com o objetivo de reconhecer padrões e objetos homogêneos (INPE, 2006). Os métodos de classificação de imagens são aplicados com o objetivo de criar representações temáticas de fenômenos, feições e objetos dispostos sobre a superfície terrestre. Estes métodos delimitam porções em que a resposta espectral dos alvos apresenta as mesmas características ou significados.

Depois de imageados, os alvos ou elementos presentes na superfície terrestre terão suas informações, expressas em reflectância ou radiância, convertidas em níveis de cinza dentro de uma cena (imagem), onde cada "pixel" tem as coordenadas espaciais x, y e a coordenada espectral $L$, que varia de banda para banda e é representada pelos níveis de cinza. O conjunto de características espectrais de um "pixel" é denotado pelo termo "atributos espectrais".

Os classificadores automáticos podem ser supervisionados ou não supervisionados (característica relativa ao grau de interação do intérprete no processo) e, ainda, pixel-a-pixel ou contextuais (quando partem da segmentação). Recentemente, buscando contribuir para que os processos automatizados alcancem melhor desempenho, surgem os classificadores orientados a objetos que, através de critérios boleanos e/ou modelagem matemática Fuzzy, oferecem recursos para que o conhecimento do especialista possa ser minimamente sistematizado e reproduzido (CRUZ et. al, 2009).

O processo de classificação baseada em objetos utiliza os polígonos gerados na segmentação para definição dos objetos de imagem a partir de um conjunto de dados, no caso, as bandas, embora possam ser agregadas variáveis de outras naturezas. As características espectrais de forma e relações de vizinhança são as informações utilizadas na descrição destes objetos. A partir destes descritores os objetos podem ser agrupados em categorias com significado ou em classes temáticas (DEFINIENS, 2010).

Cruz et. al (2007) apontam que a classificação baseada em objetos busca simular técnicas de interpre- tação visual através da modelagem do conhecimento para identificação de feições, baseada na descrição de padrões identificadores, tais como textura, cor, métrica, contexto. Reis et. al (2009) destacam que a classificação baseada em objetos veio para suprir os tradicionais classificadores que tinham como base apenas os atributos espectrais, que não permitiam o uso de dados de diferentes resoluções e que não tratavam as classes de forma individualizada.

A classificação baseada em objetos ainda se diferencia das demais por apresentar a possibilidade de se realizar multisegmentações, gerando níveis hierarquizados, incluindo ainda aspectos de multiresolução. A classificação baseada em objetos considera muitos tipos de descritores, tratando-os como parâmetros caracterizadores dos objetos, tais como: cor, textura, tamanho, forma, padrão, localização, contexto, etc. Portanto, a inserção destes elementos, ou seja, do conhecimento do intérprete no processo, consiste em uma alternativa para a distinção de alvos que espectralmente apresentam dificuldades de serem mapeados. A caracterização dos objetos da imagem não pode limitar-se apenas a atributos espectrais, pois estes muitas vezes não conseguem delimitar objetos complexos (DEFINIENS, 2010).

Neste trabalho foram classificadas 4 imagens Landsat dos anos de 1975 (MSS), 1985 (TM), 1995 (TM), 2010 (TM), aplicando a técnica de classificação baseada em objetos, no software Definiens ${ }^{\circledR}$, que apresenta um ambiente para a classificação de imagens que possibilita a adoção de segmentação em diferentes níveis de escala, a utilização de descritores variados, disponibilizados ou construídos, além da hereditariedade entre níveis e/ou classes. Será dada ênfase, exclusivamente, à modelagem Fuzzy sobre descritores espectrais, apoiada na seleção de áreas de treinamento (amostras). A análise Fuzzy fornece o grau de participação (pertinência) de um objeto para todas as classes definidas na legenda, cujos valores podem ser inseridos em novos contextos de classificação.

Depois de gerados, os mapas temáticos de cobertura e uso da terra foram inseridos em um ambiente SIG, onde foram processadas análises que forneceram subsídios para a compreensão e localização das mudanças ocorridas na BHRSJ nos últimos 35 anos e, consequentemente, forneceram elementos importantes 
para análise da evolução da paisagem na bacia.

É importante destacarmos que a tentativa inicial foi de adquirir as imagens para um mesmo mês, preferencialmente no período seco, onde o estado da bacia seria bem semelhante nos diferentes anos analisados. No entanto, devido à grande cobertura de nuvens e a indisponibilidade de algumas imagens, não foi possível adquirirmos imagens para os quatro momentos analisados dentro de um mesmo mês. A imagem de 1975 (MSS) foi adquirida no mês de agosto, e a imagem de 2010 (TM) foi adquirida no mês de setembro, enquanto as outras duas (1985 e 1995) foram adquiridas no mês de junho (fig. 2 e quadro 1). Ressalta-se, porém, que todas as datas fazem parte do período seco.

Figura 2. Cartas-Imagem (3B4G5R) para os anos de 1975, 1985, 1995 e 2010 da BHRSJ
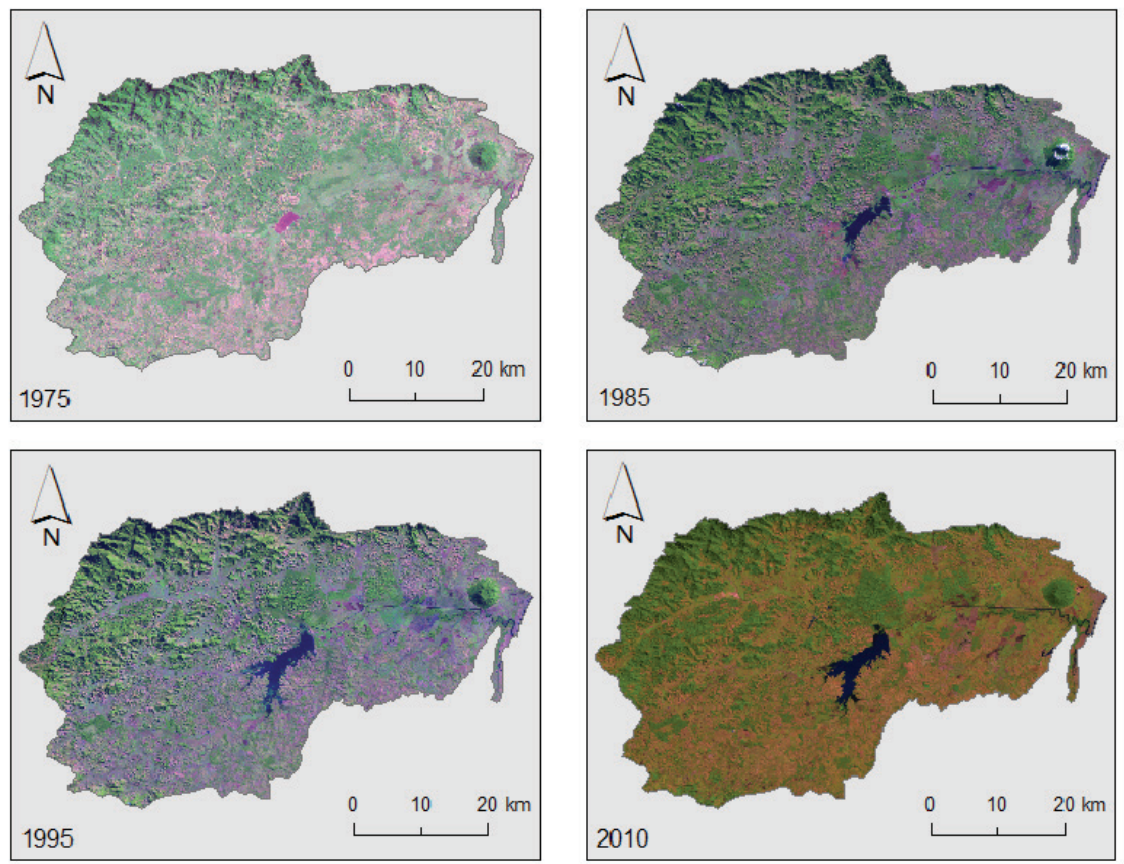

Org. dos autores.

Quadro 1: Imagens utilizadas no mapeamento da evolução do uso e cobertura da Terra na BHRSJ

\begin{tabular}{|c|c|}
\hline Imagem & Data de Geração da Imagem \\
\hline Landsat MSS & $22-08-1975$ \\
\hline Landsat 5 TM & $27-06-1985$ \\
\hline Landsat 5 TM & $07-06-1995$ \\
\hline Landsat 5 TM & $04-09-2010$ \\
\hline
\end{tabular}

Org. dos autores.

As imagens Landsat $(1975,1985,1995,2010)$ foram georreferenciadas no software Spring 5.1.3 com auxilio de uma Imagem Spot 5 (ortorretificada) do ano de 2005, com resolução espacial de 2,5 x 2,5 m, cedida pelo Laboratório de Geografia Física (LAGEF) do Departamento de Geografia da UFF. Os erros nos pontos de controle (RMS), apresentados pelo software
Spring, não ultrapassaram o valor de 0,61 (pixel) para os sensores TM (1995) e chegaram ao valor de 0.97 (pixel) para o sensor MSS (1975).

Os maiores deslocamentos encontrados entre as imagens do sensor TM foi o de $32 \mathrm{~m}$ na imagem de 1995, e na imagem MSS este valor ficou em torno de $95 \mathrm{~m}$. É importante ressaltar que a maior dificul- 
dade em georreferenciar as imagens do sensor MSS justifica-se pelas menores resoluções espectrais (4 bandas) e espaciais $(68 \times 83 \mathrm{~m})$ deste sensor, à aspectos relacionados à aquisição da imagem, além da dificuldade de encontrarmos pontos de controle na área, principalmente em razão das mudanças ocorridas na região ao longos dos últimos 35 anos.

É ainda importante mencionar que todos os mapas deste trabalho foram construídos na projeção equiretângular cilíndrica, no sistema geodésico SIRGAS 2000 e com coordenadas geográficas angulares (latitude e longitude). Os cálculos de área foram realizados sobre a projeção equivalente de Albers, que por sua característica de equivalência, apresenta menores deformações para cálculos desta natureza.

\section{CARACTERIZAÇÃO E ANÁLISE DA COBER- TURA E USO DA TERRA NOS ANOS DE 1975, 1985, 1995 E 2010.}

Como mencionado anteriormente, os mapas de Cobertura e Uso da Terra para os anos de 1975, 1985,1995 e 2010 foram gerados a partir de classificação baseada em objetos no software definiens ${ }^{\circledR}$ com o uso das bandas do visível e infravermelho do sensores MSS (Landsat 4) para a cena de 1975 e TM (Landsat 5) para os demais anos. Para os processos de modelagem e classificação foram ainda utilizados os mapas de paisagem gerados no âmbito deste trabalho. Os mapas de paisagem foram úteis para classificarmos as áreas de mangue, áreas úmidas, cordões arenosos e corpos hídricos. No entanto, os principais descritores utilizados para a classificação das classes temáticas foram os valores das médias espectrais dos alvos (segmentos) nas diferentes bandas e seus respectivos desvios padrão.

A classificação da imagem Landsat MSS (1975) ofereceu maiores obstáculos para a geração do mapa temático da Cobertura e Uso da Terra, para a escala pretendida (1:100.000), justamente em razão das diferenças existentes entre as imagens produzidas por este sensor (resoluções espacial e espectral) e as demais imagens utilizadas no trabalho (Landsat TM). As dificuldades encontradas no processamento da imagem Landsat MSS, para atender ao mapeamento em escala 1:100.000, foram desde o georreferencia- mento até a sua classificação e edição final.A definição das classes, assim como a escolha das amostras que representariam cada uma destas classes, baseou-se nos dados adquiridos em trabalho de campo. Com utilização de GPS de navegação, câmeras fotográficas e observações de campo, pôde-se avaliar a distribuição dos diferentes usos na área de estudo, assim como a sua abundância na área a ser mapeada.

A partir do mapa temático para 1975 (fig. 3), podemos perceber que a maior presença de fragmentos florestais é observada justamente na escarpa da Serra do Mar, no Morro de São João e em algumas formações residuais presentes na BHRSJ. Nas porções sudoeste e sul da bacia ocorre o predomínio das pastagens, que ocupam nitidamente as planícies, colinas e vales intramontanos de toda a bacia. É importante chamar a atenção para a grande quantidade de áreas úmidas e de corpos hídricos existentes, sobretudo nas planícies dos rios Bacaxá e São João. Devemos ainda ressaltar a presença da Lagoa de Juturnaíba na parte central da bacia.

No mapa de Cobertura e Uso da Terra para o ano de 1985 (fig. 4) podemos verificar algumas das mudanças detonadas pelo conjunto de obras realizadas entre meados da década de 70 e inicio da década de 80 , na BHRSJ. As alterações mais significativas foram a construção de canais para a drenagem de corpos hídricos e áreas úmidas que existiam nas planícies fluviais do rio São João, a retilinização do rio São João e a construção da represa de Juturnaíba. Ao compararmos as duas imagens (1975 e 1985), também percebemos a redução das áreas com coberturas naturais, fato mais facilmente percebido em regiões próximas a desembocadura da bacia. 


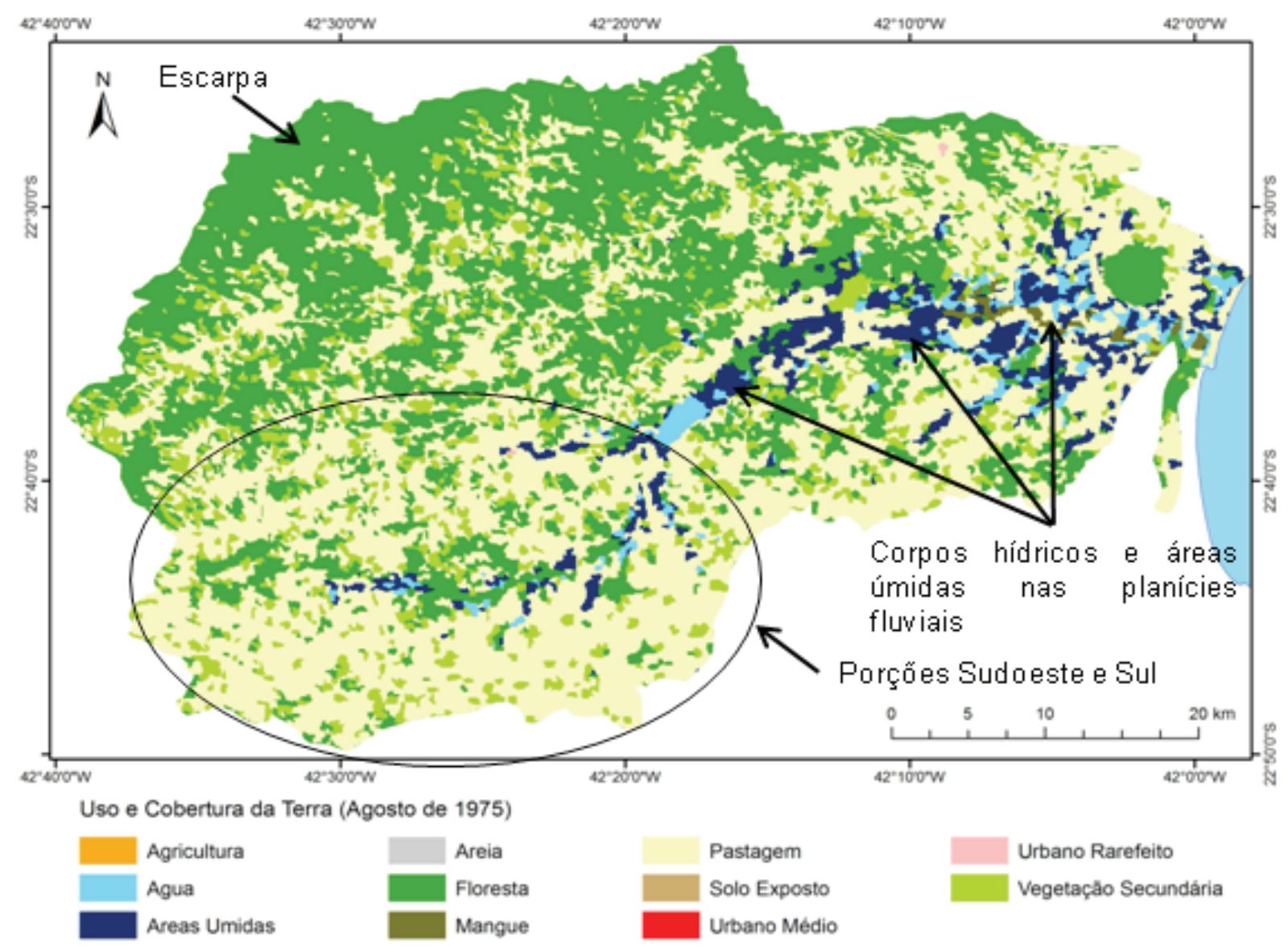

Elaboração dos autores.

Além da progressiva redução dos fragmentos florestais, a classificação da imagem Landsat TM para o ano de 1995 (fig. 5) indica um significativo aumento da ocupação urbana, sobretudo na estreita faixa costeira da bacia. Também podemos perceber claramente, mais uma vez, a redução das áreas úmidas e dos mangues, presentes no baixo curso do rio São João. Também podemos perceber o aumento do espelho d'água da represa de Juturnaíba em detrimento das áreas úmidas que existiam nos vales dos rios Bacaxá e
Capivari. É ainda relevante chamarmos atenção para o surgimento de extensas áreas de cultivo de cana-de-açúcar na porção sudeste da bacia, próximas à margem direita do baixo São João. Nos mapas dos próximos anos estes cultivos reaparecem, alternando em alguns períodos para pastagens ou áreas alagadas. 
Elaboração dos autores.

Figura 5. Cobertura e Uso da Terra na BHRSJ em 1995

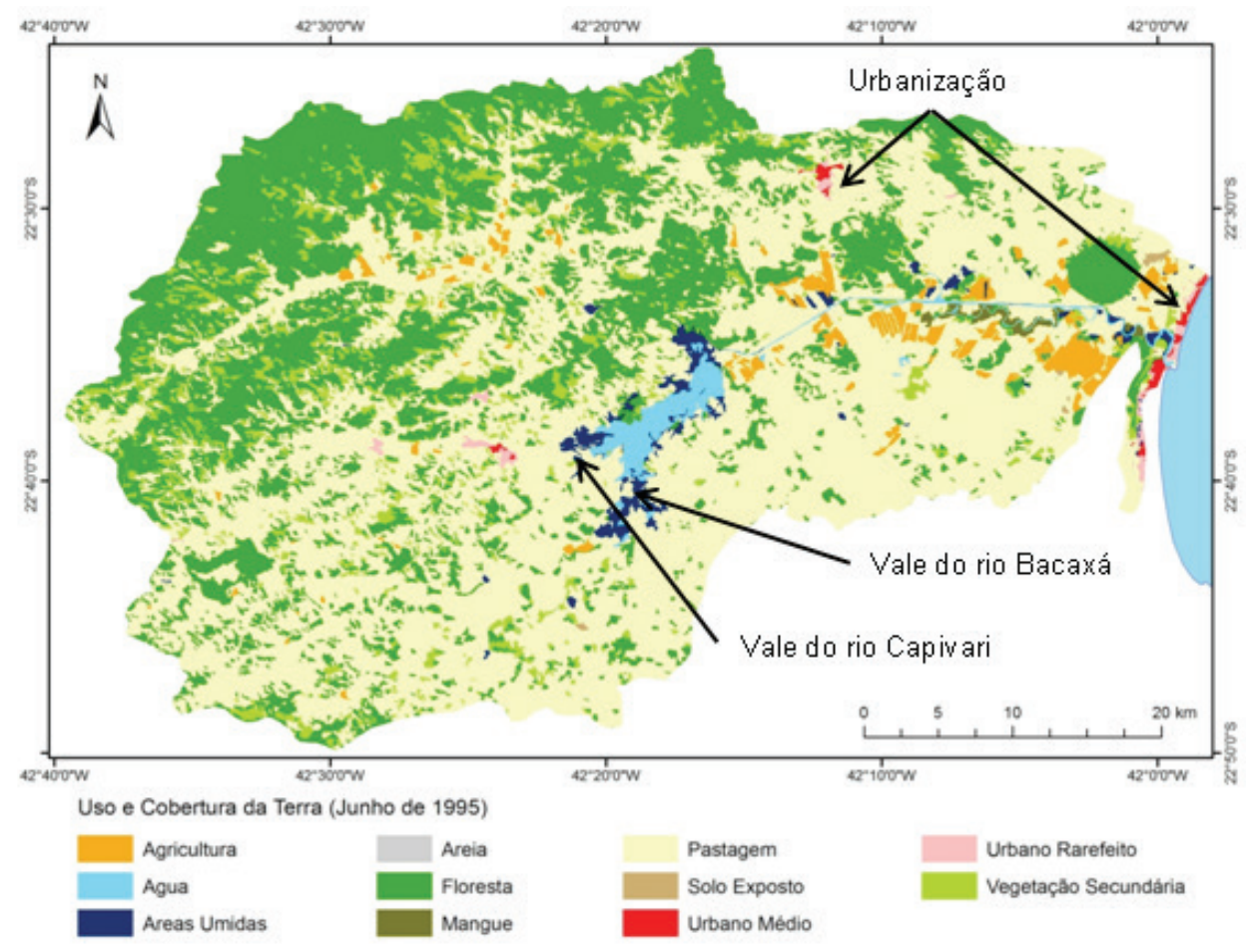

Elaboração dos autores. 
Os resultados obtidos com a classificação temática para 2010 (fig. 6) exibe um representativo crescimento e intensificação da ocupação urbana nas localidades de Barra de São João e Tamoios, sobretudo na planície costeira. Além disso, podemos perceber a recuperação de algumas pequenas áreas de pastagem ou de vegetação secundária, sobretudo nas regiões de colinas e da escarpa da Serra do Mar. Ocorre também o crescimento do espelho d'água da represa de Juturnaíba e a consequente redução das áreas úmidas que existiam em seu entorno.

Figura 6. Cobertura e Uso da Terra na BHRSJ em 2010

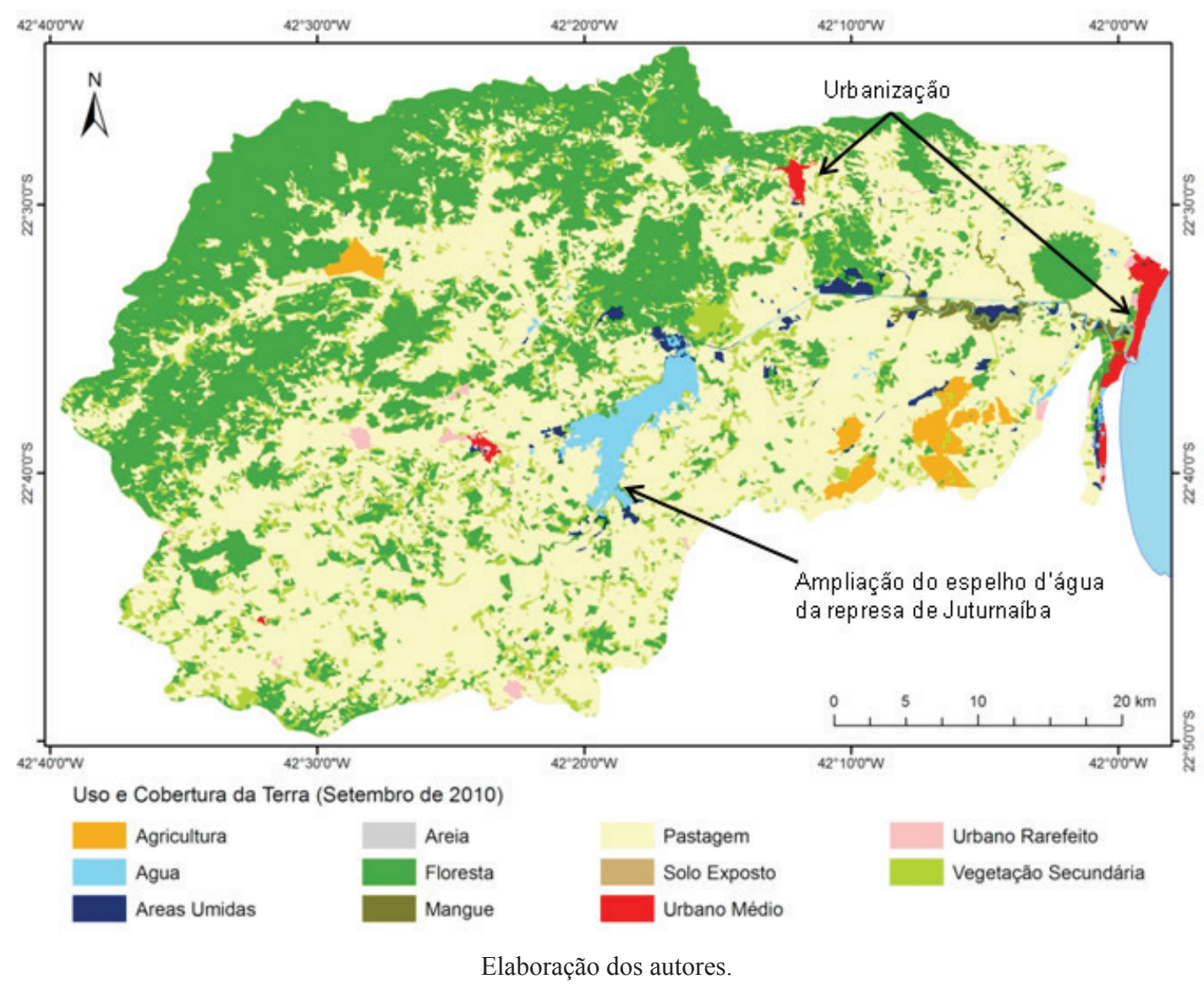

O cálculo das áreas das classes de Cobertura e Uso da Terra comprovam quantitativamente as mudanças percebidas a partir da observação dos mapas temáticos (Fig. 7 e Tabela 1). É importante chamar atenção para o crescimento das áreas florestadas entre os anos de 1995 e 2010, o progressivo decréscimo das áreas úmidas desde antes de 1975 e o acentuado aumento das áreas urbanas entre os anos de 1995 e 2010. Para todos os cálculos de área realizados foi utilizada a projeção equivalente cônica de Albers sobre vetores (shapes) na escala 1:100.000, gerados a partir de imagens Landsat 4 MSS (68 m X $83 \mathrm{~m}$ ) e imagens Landsat 5 TM (30 x 30m). 
Mapeamento da Dinâmica da Cobertura e Uso da Terra na Bacia Hidrográfica do Rio São João, RJ

Vinicius da Silva Seabra, Carla Madureira Cruz

Figura 7. Usos e Cobertura da Terra na BHRSJ para os anos de 1975, 1985, 1995 e 2010
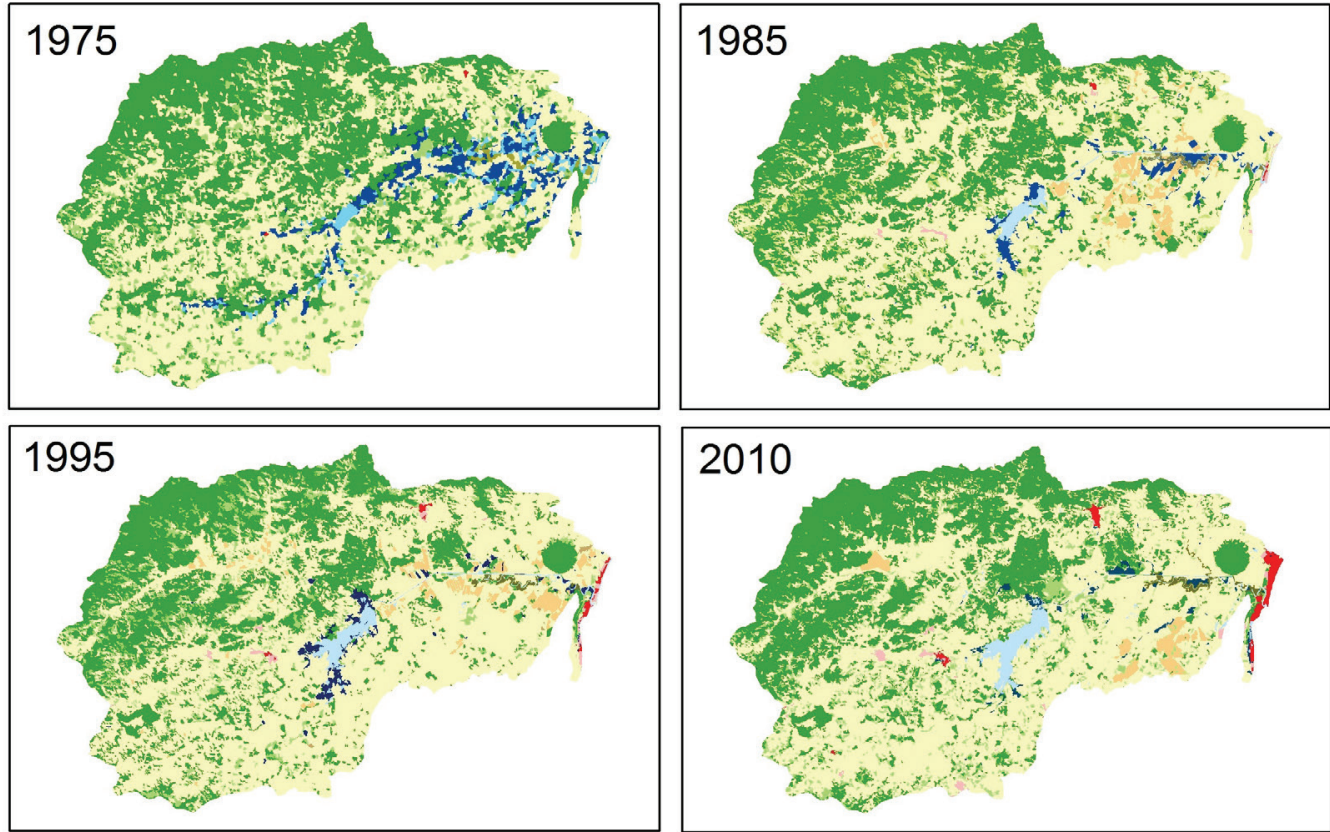

Uso e Cobertura da Terra (1975-1985-1995-2010)

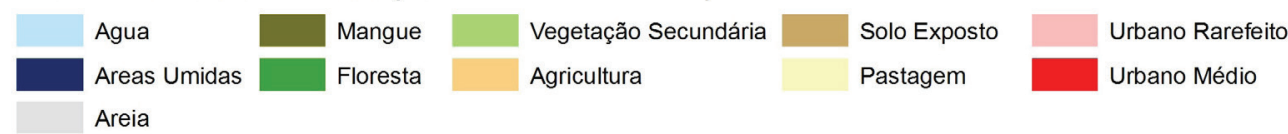

Elaboração dos autores.

Tabela 1: Quantitativo das classes de Uso e Cobertura da Terra na BHRSJ nos anos de 1975, 1985, 1995 e 2010.

\begin{tabular}{c|c|c|c|c|c|c|c|c}
$\begin{array}{c}\text { Uso e Cobertura da } \\
\text { Terra }\end{array}$ & $1975\left(\mathrm{~km}^{2}\right)$ & $\begin{array}{c}\% \\
1975\end{array}$ & $\begin{array}{c}1985 \\
\left(\mathrm{~km}^{2}\right)\end{array}$ & $\begin{array}{c}\% \\
1985\end{array}$ & $\begin{array}{c}1995 \\
\left(\mathrm{~km}^{2}\right)\end{array}$ & $\begin{array}{c}\% \\
1995\end{array}$ & $\begin{array}{c}2010 \\
\left(\mathrm{~km}^{2}\right)\end{array}$ & $\begin{array}{c}\% \\
2010\end{array}$ \\
\hline Agricultura & 0,00 & 0,00 & 52,80 & 2,50 & 49,81 & 2,35 & 30,40 & 1,44 \\
\hline Água & 41,62 & 1,97 & 19,09 & 0,90 & 28,58 & 1,35 & 36,18 & 1,71 \\
\hline Cordões Arenosos & 0,30 & 0,01 & 0,38 & 0,02 & 0,55 & 0,03 & 0,32 & 0,02 \\
\hline Floresta & 795,07 & 37,58 & 742,98 & 35,12 & 647,87 & 30,62 & 682,97 & 32,28 \\
\hline Mangue & 7,11 & 0,34 & 6,91 & 0,33 & 5,57 & 0,26 & 9,20 & 0,43 \\
\hline Ocupação Moderada & 0,00 & 0,00 & 0,87 & 0,04 & 4,52 & 0,21 & 15,71 & 0,74 \\
\hline Ocupação Rarefeita & 0,59 & 0,03 & 5,31 & 0,25 & 8,87 & 0,42 & 10,91 & 0,52 \\
\hline Solo Exposto & 0,00 & 0,00 & 0,40 & 0,02 & 1,70 & 0,08 & 0,30 & 0,01 \\
\hline Pastagem & 998,37 & 47,19 & $1.141,41$ & 53,95 & $1.214,87$ & 57,42 & $1.174,06$ & 55,49 \\
\hline Vegetação Secundária & 178,04 & 8,42 & 115,81 & 5,47 & 128,60 & 6,08 & 137,12 & 6,48 \\
\hline Áreas Úmidas & 94,54 & 4,47 & 29,68 & 1,40 & 24,70 & 1,17 & 18,47 & 0,87 \\
\hline Total & $2.115,64$ & 100 & $2.115,64$ & 100 & $2.115,64$ & 100 & $2.115,64$ & 100 \\
\hline
\end{tabular}

Soc. \& Nat., Uberlândia, 25 (2): 411-426, mai/ago/2013 


\section{ANÁLISE DA EVOLUÇÃO DA COBERTURA E USO DA TERRA NA BHRSJ ENTRE OS ANOS DE 1975, 1985, 1995 E 2010}

O estudo da evolução da Cobertura e Uso da Terra na BHRSJ entre os anos de 1975, 1985, 1995 e 2010 baseou-se no cruzamento (interseção) dos mapas temáticos digitais gerados. Para a melhor compreensão das mudanças, a legenda do mapa foi reclassificada, em diferentes etapas. Na primeira etapa, as classes cordões arenosos, floresta, mangue, e áreas úmidas, foram reclassificadas para Coberturas Naturais. Em seguida, as classes pastagem, agricultura e vegetação secundária foram agregadas em uma única classe, chamada de "Áreas de agricultura, pastagem ou vegetação secundária". As classes de ocupação moderada e rarefeita compuseram uma única classe, chamada de Ocupação Urbana, e as demais classes foram mantidas.
A partir deste processamento, tornou-se possível a análise quantitativa das mudanças ocorridas em todas as classes mapeadas para a BHRSJ. É relevante destacarmos as mudanças relativas às Coberturas Naturais que quantitativamente decresceram até 1995, apresentando um leve crescimento entre 1995 e 2010. Podemos perceber ainda que as mudanças observadas nas Coberturas Naturais apresentam fortes correlações com as alterações ocorridas na classe de Pastagem, agricultura e vegetação secundária. Ou seja, nos anos de decréscimo de coberturas naturais percebemos um aumento na classe Pastagem, agricultura e vegetação secundária, e vice-versa (fig. 8).

Figura 8. Mudanças quantitativas das coberturas naturais e áreas de pastagem, agrícolas e de vegetação secundária entre os anos de $1975,1985,1995$ e 2010

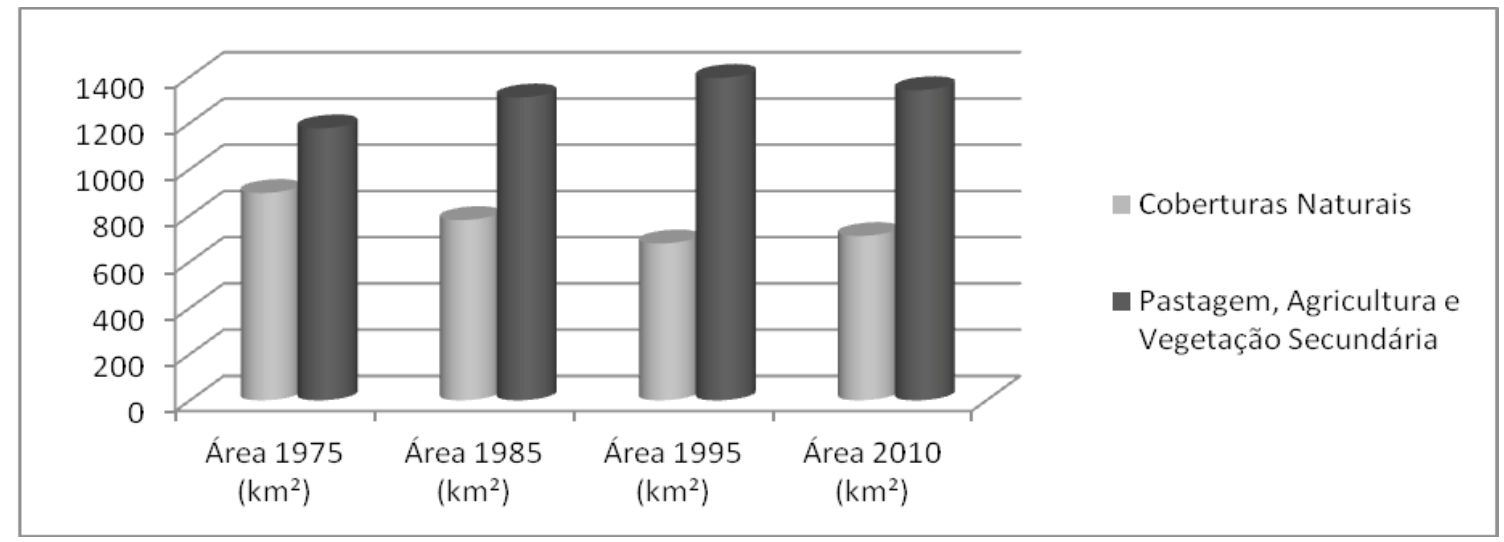

Org. dos autores.

Quando analisamos os mapas temáticos detalhadamente, podemos verificar que o aumento de coberturas naturais entre 1995 e 2010 é impulsionado principalmente pelo significativo aumento de cobertura florestal na BHRSJ. Curiosamente, percebemos também o crescimento de áreas ocupadas por corpos hídricos, que se justificam pelo aumento da área de espelho d'água da lagoa de Juturnaíba e também pelo surgimento de significativas lagoas na zona costeira e na planície fluvial do Rio São João. Estas lagoas foram artificialmente criadas por atividades de extração de areia.
O crescimento das áreas urbanas na BHRSJ também se apresenta como uma importante mudança ocorrida na BHRSJ, principalmente entre os anos de 1995 e 2010. É importante destacar mais uma vez que estas mudanças são mais significativas na planície costeira da BHRSJ, mais precisamente no distrito litorâneo de Barra de São João, pertencente ao município de Casimiro de Abreu. Este forte crescimento está associado, provavelmente, ao crescimento acelerado das cidades vizinhas de Macaé e Cabo Frio, impulsionado pela atividade de exploração de petróleo.

Os dados quantitativos apresentados na tabela 
2 permitem a observação e análise de outras significativas mudanças observadas na BHRSJ. Através dos valores de áreas descritos na tabela podemos verificar que aproximadamente $39 \%$ de toda a BHRSJ passou por mudanças de Cobertura e Uso da Terra nos últimos 35 anos, e que pelo menos $40 \%$ de toda área da bacia já possuía cobertura de pastagens e/ou vegetação secundária antes de 1975. No entanto é relevante destacarmos ainda que $21 \%$ de toda bacia possui coberturas naturais remanescentes desde antes de 1975.

Tabela 2: Quantificação das mudanças de Cobertura e Uso da Terra entre os anos de 1975 e 2010 na BHRSJ

\begin{tabular}{c|l|c} 
COD & \multicolumn{1}{|c|}{ Mudanças de Uso e Cobertura da Terra na BHRSJ entre 1975 e 2010} & $\begin{array}{c}\text { Área } \\
\left(\mathrm{km}^{2}\right)\end{array}$ \\
\hline 1 & Corpos hídricos naturais mantidos até 2010 & 8,91 \\
\hline 2 & Corpos hídricos artificiais criados entre 1975 e 2010 & 27,26 \\
\hline 3 & Corpos hídricos aterrados ou assoreados entre 1975 e 2010 & 32,71 \\
\hline 4 & $\begin{array}{l}\text { Coberturas naturais que mudaram para agricultura, pastagem ou vegetação secundária } \\
\text { entre 1975 e 1985 }\end{array}$ & 309,57 \\
\hline 5 & $\begin{array}{l}\text { Coberturas naturais que mudaram para agricultura, pastagem ou vegetação secundária } \\
\text { entre 1985 e 1995 }\end{array}$ & 170,46 \\
\hline 6 & $\begin{array}{l}\text { Coberturas naturais que mudaram para agricultura, pastagem ou vegetação secundária } \\
\text { entre 1995 e 2010 }\end{array}$ & 125,66 \\
\hline 7 & $\begin{array}{l}\text { Areas de agricultura, pastagem ou vegetação secundária que regeneraram para coberturas } \\
\text { naturais entre 1975 e 1985 }\end{array}$ & 195,20 \\
\hline 8 & $\begin{array}{l}\text { Areas de agricultura, pastagem ou vegetação secundária que regeneraram para coberturas } \\
\text { naturais entre 1985 e 1995 }\end{array}$ & 75,42 \\
\hline 9 & $\begin{array}{l}\text { Áreas de agricultura, pastagem ou vegetação secundária que regeneraram para coberturas } \\
\text { naturais entre 1995 e 2010 }\end{array}$ & 163,35 \\
\hline 10 & Áreas urbanizadas entre 1975 e 2010 & 26,03 \\
\hline 11 & Coberturas naturais desde antes de 1975 & 442,64 \\
\hline 12 & Áreas de agricultura, pastagem ou vegetação secundária desde antes de 1975 & 839,00
\end{tabular}

Org. dos autores.

A mudança de coberturas naturais para pastagens agricultura e vegetação secundária vem decaindo progressivamente no período analisado, enquanto a regeneração de áreas, ou seja, a mudança de pastagem, agricultura ou vegetação secundária para coberturas naturais sofreu um significativo aumento entre 1995 e 2010. A partir da análise dos resultados podemos observar também que as mudanças mais significativas do Uso e Cobertura da Terra ocorreram entre os anos de 1975 e 1985, coincidindo com o mesmo período de realização das mais significativas obras de engenharia na BHRSJ.

A análise das mudanças de Cobertura e Uso da Terra (1975-1985-1995-2010) indicou que ocorreram mudanças em 46,84\% da área total da Bacia, sendo que o desmatamento $(25,03 \%)$ e a regeneração $(17,71 \%)$ de áreas foram as alterações mais significativas (tabela 3.3). Dentre as áreas que não sofreram mudanças, ou seja, permanecem com o mesmo uso desde 1975, destacam-se as áreas de pastagem e agricultura, que juntas alcançam $34,56 \%$ e as áreas com coberturas naturais, que ocupam $18,23 \%$ da área total da BHRSJ (tabela 3). 
Tabela 3: Processos predominantes na BHRSJ

\begin{tabular}{l|l|l}
\multicolumn{1}{c|}{ Trajetória Evolutiva } & \multicolumn{1}{c}{ Área $\left(\mathrm{Km}^{2}\right)$} & \multicolumn{2}{c}{$\%$} \\
\hline Desmatamento & 605,59 & 25,03 \\
\hline Regeneração & 433,97 & 17,71 \\
\hline Assoreamento & 32,71 & 1,35 \\
\hline Expansão Urbana & 26,03 & 1,08 \\
\hline Formação de Novos Corpos Hídricos & 27,26 & 1,13 \\
\hline Sem mudanças (mesmo uso de 1975) & $1.290,55$ & 53,16
\end{tabular}

Org. dos autores.

O mapa de mudanças detectadas entre os anos de 1975 e 2010 na BHRSJ revela que as áreas onde ocorreram as maiores perdas de fragmentos florestais nos últimos 35 anos foram as regiões das planícies fluviais e colinas, sobretudo nas porções orientais da bacia. Além de verificarmos a ocorrência de ocupação urbana em praticamente toda planície costeira, também podemos observar a grande quantidade de antigos corpos hídricos drenados para ampliação de áreas agrícolas ou de pastagem (fig. 9).

Figura 9. Mapa de Evolução da Cobertura e Uso da Terra

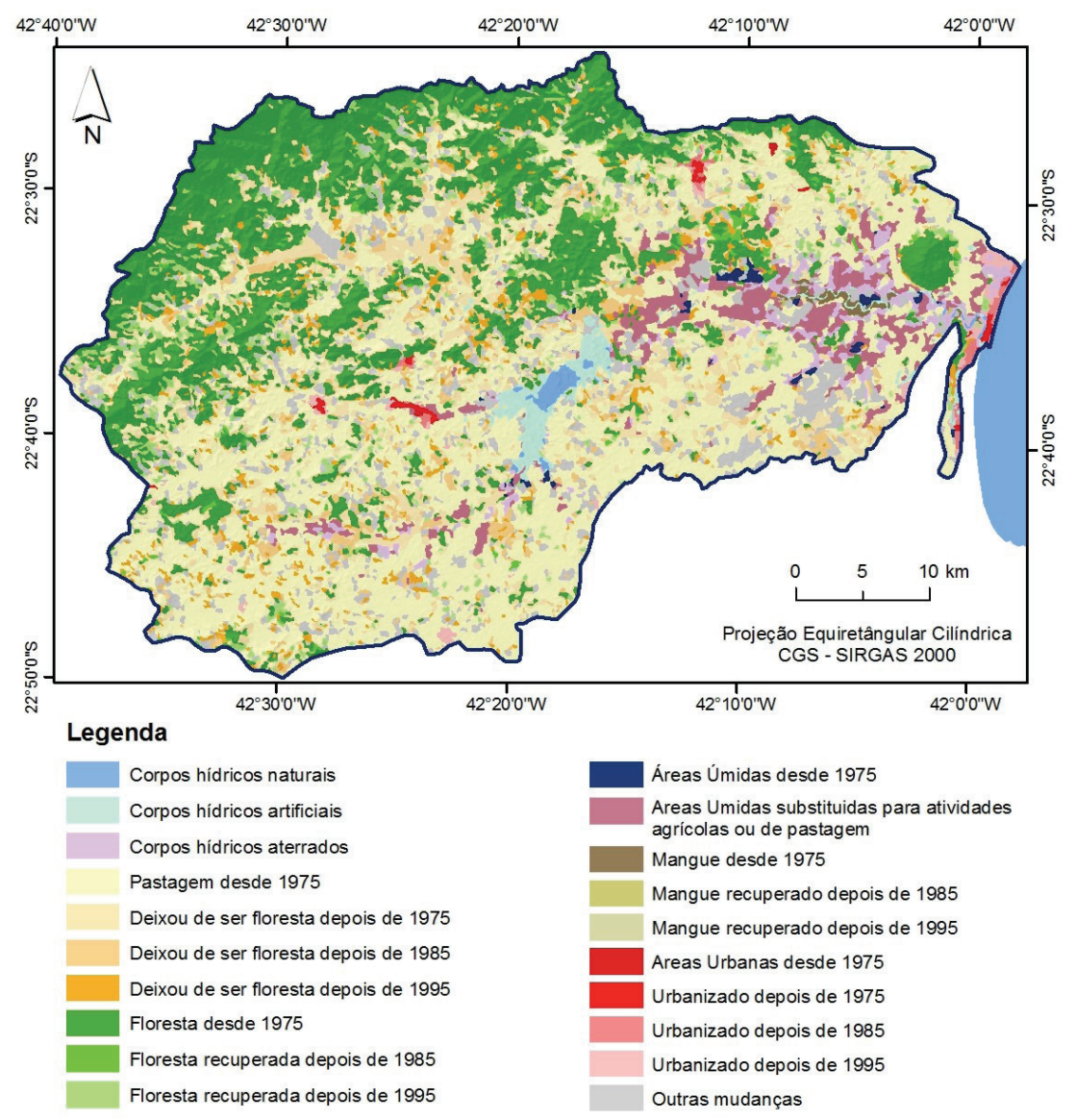

Elaboração dos autores. 
As áreas em que registramos a ocorrência de recuperação florestal estão localizadas principalmente nas regiões das escarpas, nos patamares residuais e nas regiões de morro, localizadas, sobretudo, nas porções norte e oeste da BHRSJ. Também devemos destacar no mapa a relevante presença da represa de Juturnaíba, das cavas e lagoas construídas para exploração de areia, e dos canais retilinizados que foram classificados na legenda como corpos hídricos artificiais.

As principais áreas de recuperação foram reavaliadas a partir de análises visuais mais rigorosas, realizadas sobre imagens Landsat TM, com apoio de imagens SPOT 5 disponíveis para toda BHRSJ e, ainda, com a utilização do software Google Earth.

\section{CONCLUSÕES}

A utilização de técnicas de sensoriamento remoto para a construção do mapa de uso e cobertura do solo, com utilização de classificação orientada ao objeto, mostrou resultados muito mais satisfatórios que os métodos tradicionais, o que refletiu num menor esforço de edição dos mapas finais. O levantamento de dados a partir das imagens, trabalhos de campo e de bibliografias existentes, assim como a inserção destes em um banco de dados geográficos, tornou possível a geração de informações capazes de nos indicar a ocorrência e localização de alterações relevantes ocorridas na área de estudo.

Os mapas de Cobertura e Uso da Terra revelaram que a BHRSJ tem a pastagem como uso predominante desde antes de 1975 . Os resultados demonstram que a pastagem ocupa principalmente as áreas planas ou suavemente onduladas da bacia, chegando, em muitos casos, a ocupar encostas de morros e montanhas, escarpas e vales intramontanos. Também pode-se verificar que muitas destas áreas, localizadas em domínios de morros ou montanhas, já experimentaram ou experimentam algum tipo de processo de regeneração.

Os resultados confirmam uma significativa presença de coberturas florestais, ocupando aproximadamente $32 \%$ da bacia, principalmente nas escarpas e vertentes íngremes da Serra do Mar e Patamares Residuais. Os resultados ainda indicam que as planícies aluviais e costeiras são as unidades em pior estado de conservação, fato relacionado principalmente ao crescimento urbano acelerado e à drenagem artificial para ganho de áreas para pastagem realizada na década de 70 .

As análises realizadas a partir do mapa de evolução da Cobertura e Uso da Terra e as quantificações das mudanças ocorridas na bacia nos últimos 35 anos permitiram uma compreensão mais detalhada do grande número de transformações que a BHRSJ passou nas últimas décadas. Dentre elas, podemos destacar a perda de coberturas naturais, a perda de corpos hídricos naturais e o surgimento de novos corpos hídricos (artificiais). Também foi interessante constatar que aproximadamente $60 \%$ das áreas de pastagem de toda a bacia estão presentes na paisagem desde antes de 1975.

Outro aspecto importante foi o crescimento de áreas com coberturas naturais, ocorrido entre 1995 e 2010, que foi impulsionado não somente pela queda das taxas de desmatamento, como também pelo aumento das áreas recuperadas neste período. A análise mais detalhada confirmou as expectativas de que estas áreas recuperadas estariam nas bordas de fragmentos florestais, ou ainda, seriam clareiras em áreas florestadas "preenchidas" ao longo do tempo por formações florestais.

Os resultados reforçam a hipótese de que a proximidade e contexto das áreas degradadas em relação às coberturas naturais são preponderantes para a ocorrência de recuperação florestal. As "clareiras", os vales intramontanos e as bordas de grandes fragmentos florestais foram onde mais ocorreram os processos de recuperação. Além disso, também pode-se perceber que a recuperação ocorre com maior frequência em áreas onde o processo de desmatamento é recente, o que pode ser considerada uma evidência de que estas áreas têm maior favorabilidade à recuperação.

É relevante destacarmos ainda que, as alterações sofridas ao longo dos últimos 35 anos na BHRSJ resultam em sérios impactos socioeconômicos para a população local. Os sucessivos desmatamentos ocorridos em diferentes áreas da bacia, somados ás obras de engenharia empreendidas principalmente em suas planícies fluviais têm, possivelmente, participação importante no assoreamento dos rios de toda BHRSJ, prejudicando, por exemplo, a pesca em toda região. 


\section{REFERÊNCIAS}

CARLEER, A.P. \& WOLFF E. Region-based classification potential for land-cover classification with very high spatial resolution satellite data. In: I INTERNATIONAL CONFERENCE ON OBJECT-BASED IMAGE ANALYSIS, Salzburg University, Austria. 2006. Proceedings... Austria. 2006.

CILSJ (Consórcio Intermunicipal Lagos São João). Consórcio Intermunicipal para Gestão Ambiental das Bacias da Região dos Lagos, do Rio São João e Zona Costeira. Disponível em: $<$ http://www.lagossaojoao. org.br/>. Acesso em janeiro de 2007.

CRIK, Tanja; URIARTE, M.; CORSI, F.; FLYNN, D. Forest recovery in a tropical landscape: what is the relative importance of biophyical, socioeconomic, and landscape variables? Landscape Ecology. 24, p.629-642. 2009. DOI 10.1007/s10980-009-9338-8.

CRUZ, C.B.M., ROSÁRIO, L. S.,ABREU, M. B., ALMEIDA, P. M. M., ViCENS, R.S.,CRONEMBERGUER, F.M. Classificação Orientada a Objetos na Geração do Mapa de Uso e Cobertura da Terra do estado do Rio de Janeiro. In: XIV SIMPÓSIO BRASILEIRO DE SENSORIAMENTO REMOTO, Natal, Brasil, 25-30 abril 2009, Anais... Natal: INPE, p. 7789-7796. 2009.

CRUZ, C. B. M., VICENS, R. S., SEABRA, V.S., REIS, R. B., FABER, O. A., RICHTER, M., ARNAUT, P. K. E., ARAUJO, M. Classificação orientada a objetos no mapeamento dos remanescentes da cobertura vegetal do bioma Mata Atlântica, na escala 1:250.000. XIII SIMPÓSIO BRASILEIRO DE SENSORIAMENTO REMOTO, Florianópolis, 2007. Anais... Florianópolis: INPE, 2007.

EARTH DEFINIENS (sítio na internet). The Principles of Definiens Cognition Network Technology. Disponível em: <http:/earth.definiens.com/learn/ technology $>$. Acesso em Janeiro de 2010.

DE PINHO, C. M., FEITOSA, F. and H. J. KUX: Classificação automática de cobertura do solo urbano em imagem IKONOS: Comparação entre a abordagem pixel-a-pixel e orientada a objetos. In: XII SIMPÓSIO BRASILEIRO DE SENSORIAMENTO REMOTO, Goiânia, 2005. Anais... Goiânia: INPE, 2005.

HECHT SB, KANDEL S, GOMEZ I, CUELLAR $\mathrm{N}$, ROSA H. Globalization, forest resurgence, and environmental politics in El Salvador. World Dev, 34, p.308-323, 2006.

INPE (Instituto Nacional de Pesquisas Espaciais-Brasil). Tutorial do SPRING. São José dos Campos: INPE, 2006.

JANSEN, L.J.M. \& GREGORIO, A. Di. Parametric land cover and land use classifications as tools for environmental change detection. Agriculture Ecossystems e Environment. v. 91, p.89-100, 2002.

READ L., LAWRENCE D., FOSTER D.R. Recovery of biomass following shifting cultivation in dry tropical forests of the Yucatan. Ecol Appl. v.13, p.85-97, 1993.

WALKER R. Deforestation and economic development. Can J Reg Sci. v.16, p.481-497, 2003.

REIS, R. B., CARDOSO, P. V., CRUZ, C B. M., VICENS, R. S. Classificação do Uso e Cobertura do Solo da APA do São João em uma abordagem orientada a objeto. In: XIV SIMPÓSIO BRASILEIRO DE SENSORIAMENTO REMOTO, Natal, 25-30 abril 2009. Anais... Natal: INPE, p. 7087-7094, 2009.

ROSÁRIO, L. S., CRUZ, C. B. M., TEMPONI, L. M., SANTOS, P. R. A. Análise Orientada a Objeto no Mapeamento dos Estágios Sucessionais da Vegetação na Escala 1:25.000 - um Estudo de Caso da REBIO União, RJ. In: XIV SIMPÓSIO BRASILEIRO DE SENSORIAMENTO REMOTO, Natal, 25-30 abril 2009. Anais... Natal: INPE, p. 7119-7126. 2009.

RUDEL TK, PEREZ-LUGO M, ZICHAL H. When fields revert to forest: development and spontaneous reforestation in Post-War Puerto Rico. The Professional Geographer. v.52, n.3, p.386-397, 2000. 
DOI:10.1111/0033-0124.00233.

SEABRA, V.S., SILVA G.C., CRUZ, C.B.M. The use of geoprocessing to assess vulnerability on the east coast aquifers of Rio de Janeiro State, Brazil. Environmental Geology, v.57. n.3. p.665-674, 2009. DOI 10.1007/s00254-008-1345-6.

\section{AGRADECIMENTOS}

A realização deste trabalho contou com apoio financeiro da CAPES-Brasil. 